\title{
Comparing the efficacy of continuous and pulsed ultrasound therapies in patients with lateral epicondylitis: A double-blind, randomized, placebo-controlled study
}

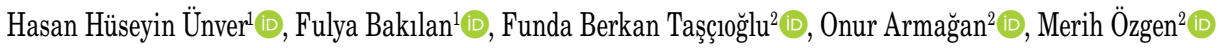 \\ ${ }^{1}$ Department of Physical Medicine and Rehabilitation, Eskişehir City Hospital, Eskişehir, Turkey \\ ${ }^{2}$ Department of Physical Medicine and Rehabilitation, Eskișehir Osmangazi University, Faculty of Medicine, Eskișehir, Turkey
}

Received: May 22, 2019 Accepted: December 08, 2019 Published online: March 04, 2021

\begin{abstract}
Objectives: The aim of this study was to investigate the efficacy of continuous and pulsed ultrasound therapies in lateral epicondylitis.

Patients and methods: A total of 51 patients (18 males, 33 females; mean age: $46.52 \pm 6.16$ years; range, 27 to 64 years) who were diagnosed with lateral epicondylitis between February 2013 and October 2014 were included. The patients were randomized to either continuous ultrasound $(n=17)$, pulsed ultrasound $(n=17)$, or placebo $(n=17)$ groups. First group received 10 sessions of continuous ultrasound therapy. The second group received 10 sessions of pulsed ultrasound therapy in a ratio of 1:4. The third group received 10 sessions of placebo treatment. The pain levels of the patients were evaluated using Visual Analog Scale (VAS). The muscle strength was evaluated using a dynamometer. For functional evaluation, Duruöz's Hand Index (DHI) and Patient-Rated Tennis Elbow Evaluation (PRTEE) scales were used. Assessments were made at baseline, at the end of therapy, and one month after therapy. The thickness of the common extensor tendon was also measured using ultrasonic imaging at baseline and at the end of therapy.

Results: At the end of the study, there was a statistically significant improvement in the rest and activation VAS scores, and DHI and PRTEE scores in both continuous and pulsed ultrasound therapy groups, compared to placebo $(\mathrm{p}<0.05)$. However, no superiority was found between the continuous and pulsed ultrasound therapy groups ( $>0.05)$. A statistically significant reduction in the common extensor tendon thickness was found only in the pulsed ultrasound therapy group $(\mathrm{p}<0.05)$.

Conclusion: Our study results show that both continuous and pulsed ultrasound applications are effective in the treatment of lateral epicondylitis.

Keywords: Lateral epicondylitis, pulsed ultrasound, therapeutic ultrasound.
\end{abstract}

Lateral epicondylitis (LE), also known as tennis elbow, has an estimated prevalence of 1 to $3 \%$, and the dominant arm is commonly affected. It more frequently occurs between 40 and 60 years and usually affects women. ${ }^{[1-3]}$ The diagnosis of LE is made clinically and it is based on a history of pain and tenderness, localized to lateral epicondyle. Although the diagnosis of LE is clear, to date, no gold-standard treatment has been established. All treatment methods have different therapeutic mechanisms of action; however, the goal of therapy is common: to improve function and reduce pain.

Physiotherapy is a conservative treatment which is usually recommended for LE. ${ }^{[4,5]}$ Ultrasound (US) has been used as a therapeutic agent in physiotherapy for decades and accepted as an adjunct modality for the management of many musculoskeletal conditions. ${ }^{[6-8]}$ It can be applied as pulsed or continuous therapy.

Corresponding author: Fulya Bakılan, MD. Eskişehir Şehir Hastanesi Fizik Tedavi ve Rehabilitasyon Kliniği, 26080 Odunpazarı, Eskişehir, Türkiye. e-mail: fulyabakilan@gmail.com 
Pulsed US (PUS) produces non-thermal effects, reduces inflammation, and increases collagen regeneration, whereas continuous US (CUS) generates thermal effects. $^{[9-13]}$

The number of the studies investigating the efficacy of therapeutic US in LE is limited and there are conflicting results on its efficacy. In some of these studies, the efficacy of PUS and CUS therapies has been examined and satisfactory effects have been described in LE patients. ${ }^{[14,15]}$ On the other hand, some authors have suggested that neither PUS nor CUS therapy is superior to placebo. ${ }^{[16-18]}$

To the best of our knowledge, there is no placebocontrolled study in the literature comparing the efficacy of PUS and CUS in the treatment of LE. In the present study, we, for the first time, aimed to investigate the therapeutic effects of CUS and PUS in LE.

\section{PATIENTS AND METHODS}

This double-blind, prospective, randomized, placebo-controlled study was carried out at the outpatient clinic of the Eskisehir Osmangazi University, Faculty of Medicine, Department of Physical Medicine and Rehabilitation between February 2013 and October 2014. A total 51 patients (18 males, 33 females; mean age: $46.52 \pm 6.16$ years; range, 27 to 64 years) who were diagnosed with LE were enrolled. Inclusion criteria were as follows: age between 18 and 70 years, having pain on the lateral side of the elbow for less than six months, tenderness over the lateral epicondyle, and pain during extension of the wrist and fingers. Exclusion criteria were as follows: upper extremity and neck disorders, other elbow pathologies, presence of tendon rupture, use of non-steroidal anti-inflammatory drugs, joint limitations due to a previous radial/ulnar fracture, previous elbow surgery, osteoporosis, malignancy, hemophilia, neurological deficit(s) in the ipsilateral upper limb, and cognitive disfunction. After a detailed history taking and physical examination, routine hematological and biochemical analyses were performed in all patients. In addition, elbow radiographies were taken. A written informed consent was obtained from each patient. The study protocol was approved by the Institutional Review Board of Eskisehir Osmangazi University, Faculty of Medicine (14.05.2013/05). The study was conducted in accordance with the principles of the Declaration of Helsinki.

\section{Randomization}

The patients who met the inclusion criteria were randomly assigned to three groups using a secure system of numbered 1-2-3 opaque closed envelopes. The physiotherapist opened the envelopes and applied the treatment. The physician who made the clinical assessments was blind to randomization and treatment allocation.

\section{Treatment protocol}

In Group 1 (CUS group, $\mathrm{n}=17$ ), continuous ultrasonic waves of $1.5 \mathrm{MHz}$ frequency and $1 \mathrm{~W} / \mathrm{cm}^{2}$ power were applied with a $5-\mathrm{cm}$ diameter applicator (Sonopuls 434; Enraf Nonius, Delft, Netherlands) for $5 \mathrm{~min}$ per session. The patients were in the sitting position, and an acoustic gel containing no pharmacological active substance was applied. Ultrasound was, then, applied to the lateral epicondyle in circular movements with the probe at right angles to ensure maximum absorption of the energy.

In Group 2 (PUS group, $\mathrm{n}=17$ ), the same US equipment was set at a frequency of $1.5 \mathrm{MHz}$ and a power of $1 \mathrm{~W} / \mathrm{cm}^{2}$ and a pulsed mode duty cycle of 1:4. The duration of US applied and the posture of the patient treated were as described for the CUS group.

The patients in Group 3 (placebo US group, $n=17$ ) received a sham US application, where the same US device as described above seemed to be working, but without delivering any output. The treatment was applied to the target in the same manner as described above, using the acoustic gel, and for 5 min per session.

All US therapies were performed once a day for 5 min, five days a week, for a total of two weeks. Clinical assessments were performed at baseline, at two and six weeks by a single physician who was blind to the treatment allocation.

\section{Clinical assessment}

The Visual Analog Scale (VAS), grip strength, Duruöz Hand Index (DHI), and Patient-Rated Tennis Elbow Evaluation (PRTEE) were used for the clinical follow-up and evaluation of the patients. The severity of pain at rest and on movement in the past $24 \mathrm{~h}$ was assessed using the VAS, consisting of $10-\mathrm{cm}$ horizontal lines with anchor points of 0 (no pain) and 10 (maximum pain). ${ }^{[19,20]}$

The grip strength was measured using a Baseline ${ }^{\infty}$ hydraulic hand dynamometer (Baseline Evaluation 
Instruments, NY, USA). ${ }^{[21]}$ The patient sat on a chair in a comfortable position ( 0 degree of shoulder abduction and 90 degrees of elbow flexion). The application was explained to the patient in detail. Each measurement was carried out three times, while taking a resting period of $2 \mathrm{~min}$ between each measurement. The average score of three measurements was calculated and recorded in pounds.

The DHI consists of 18 questions regarding manual tasks which are frequently carried out while cooking, washing, dressing, etc. The patient is asked to evaluate the difficulty which he/she has in carrying out these tasks (from 0: no difficulty, to 5: impossible). ${ }^{[22]}$

The PRTEE assesses the average pain and function of the affected arm during the preceding week. It consists of two parts, one for assessing pain and one for assessing function using a Numeric Rating Scale ranging from 0 to 10 , with five and 10 questions, respectively. ${ }^{[23,24]}$

\section{Ultrasonographic assessment}

Ultrasonographic assessment was performed by an experienced radiologist using the Toshiba Aplio $^{\text {ma }}$ 500A machine (Toshiba Medical Systems Co., Otawara, Japan) with an $8-\mathrm{MHz}$ linear probe, while the patient was sitting (70 degrees of elbow flexion, neutral position of wrist, and semiflexion position of fingers). Diagnostic US showed thickening of the origin of the common extensor tendon from the lateral humeral epicondyle and the maximum thickness was documented before and after treatment. ${ }^{[25]}$

\section{Statistical analysis}

Statistical analysis was performed using the IBM SPSS version 22.0 software (IBM Corp., Armonk, NY, USA). Continuous variables were expressed in mean \pm standard deviation (SD) or median (min$\max$ ), while categorical variables were expressed in number and frequency. The distribution of normality was checked using the Shapiro-Wilk test. Normally distributed variables were analyzed using the paired t-test or one-way analysis of variance (ANOVA) with repeated measures between the baseline and at two and six weeks. One-way ANOVA was performed for intergroup comparison of continuous variables. A $p$ value of $<0.05$ was considered statistically significant.

\section{RESULTS}

There were no significant differences in the baseline characteristics of the patients randomized in this study (Table 1).

The VAS-movement, VAS-rest, grip strength, DHI, and PRTEE scores were similar in all groups at baseline. Compared to baseline, at two weeks, significant improvements were observed in the VAS-movement, grip strength, DHI, and PRTEE scores in all groups $(\mathrm{p}<0.05)$ However, compared to baseline, at six weeks, the VAS-movement $(\mathrm{p}<0.05)$, grip strength $(\mathrm{p}<0.05)$, DHI (CUS group: $\mathrm{p}<0.05$, PUS group: $p<0.01)$, and PRTEE scores $(p<0.01)$ were significantly improved only in the CUS and PUS groups. Compared to baseline, the comparisons among the three groups at two and six weeks revealed a significant difference in all clinical

\section{TABLE 1}

Baseline demographic characteristic of patients

\begin{tabular}{|c|c|c|c|c|c|c|}
\hline & \multicolumn{2}{|c|}{ Group $1(n=17)$} & \multicolumn{2}{|c|}{ Group $2(n=17)$} & \multicolumn{2}{|c|}{ Group $3(n=17)$} \\
\hline & $\mathrm{n}$ & Mean \pm SD & $\mathrm{n}$ & Mean \pm SD & $\mathrm{n}$ & Mean \pm SD \\
\hline Age (year) & & $45.3 \pm 7.5$ & & $47.2 \pm 4.2$ & & $47.1 \pm 6.8$ \\
\hline \multicolumn{7}{|l|}{ Sex } \\
\hline Male & 7 & & 5 & & 6 & \\
\hline Female & 10 & & 12 & & 11 & \\
\hline Duration of symptoms (month) & & $3.5 \pm 1.9$ & & $3.7 \pm 2.0$ & & $3.7 \pm 2.1$ \\
\hline \multicolumn{7}{|l|}{ Dominant extremity } \\
\hline Right & 15 & & 15 & & 14 & \\
\hline Left & 2 & & 2 & & 3 & \\
\hline \multicolumn{7}{|l|}{ Affected extremity } \\
\hline Right & 12 & & 14 & & 14 & \\
\hline Left & 5 & & 3 & & 3 & \\
\hline
\end{tabular}




\begin{tabular}{|c|c|c|c|c|}
\hline \multicolumn{5}{|c|}{$\begin{array}{c}\text { TABLE } 2 \\
\text { Comparison of clinical variables at baseline, two weeks, and six weeks }\end{array}$} \\
\hline & Group $1(n=17)$ & Group $2(n=17)$ & Group $3(n=17)$ & \\
\hline & Mean \pm SD & Mean \pm SD & Mean \pm SD & $P$ value \\
\hline \multicolumn{5}{|l|}{ VAS-rest } \\
\hline Baseline (B) & $3.0 \pm 1.2$ & $3.2 \pm 1.3$ & $3.3 \pm 1.4$ & \\
\hline Second week (2w) & $2.2 \pm 1.8$ & $2.3 \pm 1.4$ & $2.9 \pm 1.5$ & $\begin{array}{l}1-3:<0.05 \\
2-3:<0.05\end{array}$ \\
\hline Sixth week (6w) & $2.1 \pm 1.5$ & $2.1 \pm 1.4$ & $2.8 \pm 1.8$ & $\begin{array}{l}1-3:<0.05 \\
2-3:<0.05\end{array}$ \\
\hline$P$ value & $>0.05$ & $>0.05$ & $>0.05$ & \\
\hline \multicolumn{5}{|l|}{ VAS-movement } \\
\hline Baseline (B) & $7.8 \pm 1.8$ & $8.1 \pm 1.6$ & $7.6 \pm 2.0$ & \\
\hline Second week (2w) & $5.4 \pm 1.5$ & $5.8 \pm 1.4$ & $5.9 \pm 1.9$ & $\begin{array}{l}1-3:<0.05 \\
2-3:<0.05\end{array}$ \\
\hline Sixth week (6w) & $4.1 \pm 1.9$ & $3.7 \pm 1.6$ & $6.3 \pm 2.2$ & $\begin{array}{l}1-3:<0.05 \\
2-3:<0.05\end{array}$ \\
\hline$P$ value & $\begin{array}{l}\text { B-2w: }<0.05 \\
\text { B-6w: }<0.05\end{array}$ & $\begin{array}{c}\text { B-2w: }<0.05 \\
\text { B-6w: }<0.05 \\
2 w-6 w:<0.05\end{array}$ & B-2w: $<0.05$ & \\
\hline \multicolumn{5}{|l|}{ Grip strength } \\
\hline Baseline (B) & $24.3 \pm 8.4$ & $25.4 \pm 8.3$ & $22.0 \pm 9.4$ & \\
\hline Second week (2w) & $26.6 \pm 13.5$ & $27.3 \pm 11.2$ & $23.3 \pm 13.0$ & \\
\hline Sixth week (6w) & $26.4 \pm 10.7$ & $27.6 \pm 9.4$ & $22.8 \pm 11.6$ & \\
\hline$P$ value & $\begin{array}{l}\text { B-2w: }<0.05 \\
\text { B-6w: }<0.05\end{array}$ & $\begin{array}{l}\text { B-2w: }<0.05 \\
\text { B-6w: }<0.05\end{array}$ & B-2w: $<0.05$ & \\
\hline \multicolumn{5}{|l|}{ Duruöz Hand Index } \\
\hline Baseline (B) & $33.4 \pm 14.9$ & $37.1 \pm 12.2$ & $34.0 \pm 15.4$ & \\
\hline Second week (2w) & $19.1 \pm 13.8$ & $22.4 \pm 16.3$ & $27.7 \pm 14.6$ & $\begin{array}{l}1-3:<0.05 \\
2-3:<0.05\end{array}$ \\
\hline Sixth week (6w) & $16.7 \pm 12.5$ & $11.4 \pm 11.6$ & $30.4 \pm 16.2$ & $\begin{array}{l}1-3:<0.05 \\
2-3:<0.05\end{array}$ \\
\hline$P$ value & $\begin{array}{l}\text { B-2w: }<0.05 \\
\text { B-6w: }<0.05\end{array}$ & $\begin{array}{c}\text { B-2w: }<0.05 \\
\text { B-6w: }<0.01 \\
2 w-6 w:<0.05\end{array}$ & B-2w: $<0.05$ & \\
\hline \multicolumn{5}{|c|}{ Patient-Rated Tennis Elbow Evaluation } \\
\hline Baseline (B) & $51.7 \pm 9.6$ & $55.4 \pm 9.3$ & $50.7 \pm 11.5$ & \\
\hline Second week $(2 \mathrm{w})$ & $33.2 \pm 9.8$ & $37.9 \pm 10.1$ & $44.3 \pm 12.1$ & $\begin{array}{l}1-3:<0.05 \\
2-3:<0.05\end{array}$ \\
\hline Sixth week (6w) & $26.2 \pm 8.8$ & $24.4 \pm 8.7$ & $45.5 \pm 10.7$ & $\begin{array}{l}1-3:<0.05 \\
2-3:<0.05\end{array}$ \\
\hline$P$ value & $\begin{array}{l}\text { B-2w: }<0.05 \\
\text { B-6w: }<0.01\end{array}$ & $\begin{array}{c}\text { B-2w: }<0.05 \\
\text { B-6w: }<0.01 \\
2 w-6 w:<0.05\end{array}$ & B-2w: $<0.05$ & \\
\hline
\end{tabular}

\begin{tabular}{|lcccc|}
\hline \multicolumn{2}{|c|}{ TABLE 3 } & & & \\
Comparison of ultrasonographic variables at baseline, two weeks, and six weeks
\end{tabular}


parameters, except for grip strength in favor of CUS and PUS groups than the placebo group $(\mathrm{p}<0.05)$ (Table 2).

The thickness of the origin of the common extensor tendon was similar at baseline. At the end of the treatment (Week 2), however, ultrasonographic assessment revealed a significant decrease in the thickness of common extensor tendon in favor of the PUS groups, compared to both placebo and CUS groups $(\mathrm{p}<0.05)$ (Table 3$)$.

No systemic or local side effects were reported during or after the treatment.

\section{DISCUSSION}

In this double-blind, randomized, placebocontrolled study, we evaluated the efficacy of CUS and PUS therapies in patients with LE. Our study results showed significant improvements in activity pain, grip strength, DHI, and PRTEE scores at two weeks in all groups. However, this clinical improvement continued over the six-week period only in the CUS and PUS groups. Furthermore, comparisons among the three groups showed that significant improvements were observed in all clinical parameters, except for the grip strength in favor of CUS and PUS groups at two and six weeks of therapy. Ultrasonographic measurements of the common extensor tendon thickness showed a significant improvement only in the PUS.

Despite its widespread use, the efficacy of therapeutic US in LE has been only subjected to a limited number of studies, and the results of these studies are somewhat conflicting. In a 12-week, randomized study including 49 patients with LE, Murtezani et al. ${ }^{[26]}$ applied a combined exercise and PUS therapy ( $1 \mathrm{MHz}, 1.5 \mathrm{~W} / \mathrm{cm}^{2}$ for 5 to $7 \mathrm{~min}$ per session, totally 18 sessions) to the first group. The second group was the corticosteroid injection group. In the US group, significant improvements were demonstrated for VAS, PRTEE pain scores, PRTEE function scores, and painfree grip strength compared to the corticosteroid group. In another randomized, placebo-controlled study, the effectiveness of PUS was compared with placebo in 76 patients with LE. ${ }^{[27]}$ Pulsed ultrasound was applied with a frequency of $1 \mathrm{MHz}, 1 \mathrm{~W} / \mathrm{cm}^{2}$, and in a pulsed mode 1:4 for $10 \mathrm{~min}$ per session. After 12 sessions of treatment, significant improvements were achieved in pain scores and grip strength in the PUS group compared to the placebo group. Similarly, in a randomized, placebo-controlled study in which the CUS $\left(1 \mathrm{MHz}, 1.5 \mathrm{~W} / \mathrm{cm}^{2}\right.$ for 5 min per session, totally 15 sessions) was compared with placebo, the VAS-pain, Disabilities of the Arm, Shoulder, and Hand Index, and Short Form-36 (SF-36) scores improved significantly in the CUS group, compared to placebo. ${ }^{[14]}$ Kachanathu and Vellapallil ${ }^{[28]}$ also reported similar improvements in their prospective, randomized study. Twenty patients with subacute LE were included in this study, and PUS and CUS were applied in addition to the conventional physiotherapy exercises. Both groups received a treatment with an intensity of 1.5 $\mathrm{W} / \mathrm{cm}^{2}$ by $1 \mathrm{MHz}$ US machine for $8 \mathrm{~min}$ for a total of 12 sessions. The PUS was given with an on-to-off ratio of one to four rate. The results showed that the clinical improvements were statistically significantly greater in patients receiving PUS therapy. Despite some differences in methodology, the results of our study are consistent with these studies.

On the other hand, there are some studies showing that US therapy is not superior to placebo in LE. In a double-blind, randomized study by D'Vaz et al., ${ }^{[15]}$ the improvements in the VAS, PRTEE, and grip strength in patients receiving PUS therapy $\left(1.5 \mathrm{MHz}, 3 \mathrm{~W} / \mathrm{cm}^{2}\right.$ for 20 min per session, totally 15 sessions) were not significantly different from the placebo group at six and 12 weeks. In another randomized study by Lundeberg et al. ${ }^{[17]}$ including 99 patients with LE, the patients were divided into three groups. The CUS therapy $(1 \mathrm{MHz}$, $1 \mathrm{~W} / \mathrm{cm}^{2}$ for $10 \mathrm{~min}$ per session, totally 10 sessions, two days in a week) was applied to the first group and placebo was given to the second group. The third group was the control group and they were only advised to rest for five weeks. Compared to the control group, a significant improvement was observed in the US group; however, there was no statistically significant difference compared to the placebo group. Although the US dose applied in our study was similar to these studies, the results are different. These conflicting results may be due to differences among the patients included in the studies. Of note, the duration of symptoms of our patients was less than six months, while the duration of symptoms of both D'Vaz et al. ${ }^{[15]}$ and Lundeberg et al.'s ${ }^{[17]}$ studies was more than six months.

Review of the literature reveals no controlled study comparing the efficacy of CUS and PUS with placebo in LE. Due to the differences in the methodology of this study, it would not be appropriate to compare the results with the findings of the aforementioned studies. In addition, therapeutic US therapy was used in many previous studies with other treatment modalities, particularly with exercise therapy. Despite 
the differences in methodology, the results of some of the studies mentioned above are similar to our results, indicating that both CUS and PUS therapies seem to be superior to placebo.

Therapeutic US is used in various musculoskeletal disorders and it converts electrical energy into an acoustic waveform, which is, then, converted into heat and, then, passes through tissues of varying resistance. ${ }^{[29]}$ The US therapy is reported to reduce edema, relieve pain, and accelerate tissue repair. ${ }^{[30-32]}$ The PUS produces non-thermal effects, whereas CUS generates thermal effects. ${ }^{[30]}$ Analgesia may be the result of increased capillary permeability and tissue metabolism, the enhancement of fibrous tissue extensibility, declining muscle spasm and the elevation of the pain threshold by thermal mechanisms. ${ }^{[30-33]}$ The PUS has been recommended for acute pain and inflammation. It changes the cellular environment, increases membrane permeability, activates the degranulation of macrophages and mast cells, enhances proliferation of fibroblasts, and affects wound contraction and protein synthesis by influencing the acoustic current and cavitation. ${ }^{[13,29,31]}$

Lateral epicondylitis most commonly occurs at the tenoperiosteal junction, and granulation tissue appears in this area. The main problem is the rapid maturation of these granulation tissues and the scar tissue has never a chance to fully heal. ${ }^{[34,35]}$ Despite all these pathophysiological evidences, there is a limited number of studies in the literature evaluating the common extensor tendon thickness in LE. Unlike our study, in a single-blind, randomized study in 59 patients with LE, Gündüz et al. ${ }^{[36]}$ compared combined US $\left(1 \mathrm{~W} / \mathrm{cm}^{2}\right.$ for $5 \mathrm{~min}$ ), massage and hot pack therapy with extracorporeal shock wave therapy and local steroid injection. There was no significant improvement in the common extensor tendon thickness in any of the three groups. In our study, however, a significant improvement in the common extensor tendon thickness was found only in the PUS group.

There are also studies showing that PUS activates collagen synthesis and regeneration. In a placebocontrolled study by Aktas, ${ }^{[37]} 45$ patients with a pressure wound were divided into three groups. The PUS therapy $\left(0.5 \mathrm{~W} / \mathrm{cm}^{2}\right)$ was applied to the first group, CUS therapy $\left(1 \mathrm{~W} / \mathrm{cm}^{2}\right)$ was applied to the second group, and placebo was given to the third group. Treatment protocols were applied for $5 \mathrm{~min}$ per session for totally 15 sessions. A statistically significant decrease in the wound size was observed only in the
PUS group. In our study, the thickness of the common extensor tendon decreased only in the PUS group. This finding may be related to the underlying mechanisms (i.e., anti-inflammatory effects), as mentioned above.

Furthermore, in our study, the placebo group also showed a statistically significant improvement in the movement pain, DHI, and PRTEE scores. This condition is known as the placebo effect which is mostly related to the patients' beliefs about the treatment and physician-patient relationship. In addition, a placebo analgesic effect is caused by the release of endogenous opioids. ${ }^{[38,39]}$

Nonetheless, there are some limitations to this study. First, only the short-term effects of therapeutic US were able to be evaluated. Therefore, further well-designed studies with long-term follow-up are needed. Second, depending on the inclusion criteria, only the patients who had LE symptoms less than six months were enrolled, which limited the number of the patients included in the study. Third, we were unable to perform a power analysis before the study. Fourth, in our study, US therapy was not combined with other treatment modalities, such as exercise therapy. However, it can be discussed whether it is a true limitation: if a combined treatment was applied, the real effectiveness of US could not have been evaluated accurately. Finally, in the literature, different doses, intensity, and duration of US in different dimensions have been examined. Therefore, the results of clinical trials should be discussed in the light of this concern.

In conclusion, our study results indicate that both CUS and PUS therapies are effective in pain relief and functional improvement in LE. However, there is still no consensus on optimal therapeutic US parameters and further well-designed trials are needed to confirm these findings.

Declaration of conflicting interests

The authors declared no conflicts of interest with respect to the authorship and/or publication of this article.

Funding

The authors received no financial support for the research and/or authorship of this article.

\section{REFERENCES}

1. Waugh EJ, Jaglal SB, Davis AM, Tomlinson G, Verrier MC. Factors associated with prognosis of lateral epicondylitis after 8 weeks of physical therapy. Arch Phys Med Rehabil 2004;85:308-18.

2. Vaquero-Picado A, Barco R, Antuña SA. Lateral epicondylitis of the elbow. EFORT Open Rev 2017;1:391-7. 
3. Martinez-Silvestrini JA, Newcomer KL, Gay RE, Schaefer MP, Kortebein P, Arendt KW. Chronic lateral epicondylitis: comparative effectiveness of a home exercise program including stretching alone versus stretching supplemented with eccentric or concentric strengthening. J Hand Ther 2005;18:411-9.

4. Mandiroğlu S, Bal A, Gurçay E, Cakcı A. Comparison of the effects of non-steroidal anti-inflammatory drugs, steroid injection and physical therapy in lateral epicondylitis. Turk J Phys Med Rehab 2007;53:104-7.

5. Akkurt S, Yilmaz A, Saka T. A comparison of extracorporeal shock wave therapy, physiotherapy, and local steroid injection in treatment of lateral epicondylitis. Turk J Phys Med Rehab 2016;1:37-44.

6. Howitt SD. Lateral epicondylosis: a case study of conservative care utilizing ART and rehabilitation. J Can Chiropr Assoc 2006;50:182-9.

7. Aaron SE, Delgado-Diaz DC, Kostek MC. Continuous Ultrasound Decreases Pain Perception and Increases Pain Threshold in Damaged Skeletal Muscle. Clin J Sport Med 2017;27:271-7.

8. Tikiz C, Duruöz T, Ünlü Z, Cerrahoglu L, Yalcinsoy E. Comparison of the efficacy of low-level laser therapy and pulsed ultrasound treatment in carpal tunnel syndrome: A placebo-controlled study. Turk J Phys Med Rehab 2013,59:201-8

9. Sarı H. Hareket sistemi hastalıklarında fiziksel tıp yöntemleri. In: Karamehmetoğlu ŞS, editör. Derin isıtıcılar. İstanbul: Nobel Tip Kitabevleri; 2002. s. 51-60.

10. Wilder RP, Jenkins J, Seto C. Treatment techniques and special equipment. In: Braddom RL, editor. Physical medicine \& rehabilitation. 3th ed. Philadelphia: Saunders Elsevier Inc; 2007. p. 413-36.

11. Yazmalar L, Sarıyıldız MA, Batmaz İ, Alpaycı M, Burkan YK, Özkan Y, et al. Efficiency of therapeutic ultrasound on pain, disability, anxiety, depression, sleep and quality of life in patients with subacromial impingement syndrome: A randomized controlled study. J Back Musculoskelet Rehabil 2016;29:801-7.

12. Sánchez AG, Andrade EL, Marsal JV, Tauste LA, Mingot CG, Monge JL, et al. A study to evaluate the effect of ultrasound treatment on nodules in multiple sclerosis patients. Int J Neurosci 2017;127:404-11.

13. Tan JC, editor. Practical manual of physical medicine and rehabilitation. 2nd ed. Philadelphia: Mosby; 2006.

14. Akin C, Oken O, Koseoglu BF. Short-term effectiveness of ultrasound treatment in patients with lateral epicondylitis: randomized, single-blind, placebo-controlled, prospective study. Turk J Rheumatol 2010;25:50-5.

15. D'Vaz AP, Ostor AJ, Speed CA, Jenner JR, Bradley M, Prevost AT, et al. Pulsed low-intensity ultrasound therapy for chronic lateral epicondylitis: a randomized controlled trial. Rheumatology (Oxford) 2006;45:566-70.

16. Haker E, Lundeberg T. Pulsed ultrasound treatment in lateral epicondylalgia. Scand J Rehabil Med 1991;23:1158.

17. Lundeberg $\mathrm{T}$, Abrahamsson $\mathrm{P}$, Haker E. A comparative study of continuous ultrasound, placebo ultrasound and rest in epicondylalgia. Scand J Rehabil Med 1988;20:99-101.
18. Oken O, Kahraman Y, Ayhan F, Canpolat S, Yorgancioglu ZR, Oken OF. The short-term efficacy of laser, brace, and ultrasound treatment in lateral epicondylitis: a prospective, randomized, controlled trial. J Hand Ther 2008;21:63-7.

19. Rosenberg N, Soudry M, StahlS. Comparison of two methods for the evaluation of treatment in medial epicondylitis: pain estimation vs grip strength measurements. Arch Orthop Trauma Surg 2004;124:363-5.

20. Svernlöv B, Adolfsson L. Non-operative treatment regime including eccentric training for lateral humeral epicondylalgia. Scand J Med Sci Sports 2001;11:328-34.

21. Wuori JL, Overend TJ, Kramer JF, MacDermid J. Strength and pain measures associated with lateral epicondylitis bracing. Arch Phys Med Rehabil 1998;79:832-7.

22. Duruöz MT, Poiraudeau S, Fermanian J, Menkes CJ, Amor $B$, Dougados $M$, et al. Development and validation of a rheumatoid hand functional disability scale that assesses functional handicap. J Rheumatol 1996;23:1167-72.

23. Overend TJ, Wuori-Fearn JL, Kramer JF, MacDermid JC. Reliability of a patient-rated forearm evaluation questionnaire for patients with lateral epicondylitis. J Hand Ther 1999;12:31-7.

24. Altan L, Ercan I, Konur S. Reliability and validity of Turkish version of the patient rated tennis elbow evaluation. Rheumatol Int 2010;30:1049-54.

25. Struijs PA, Spruyt M, Assendelft WJ, van Dijk CN. The predictive value of diagnostic sonography for the effectiveness of conservative treatment of tennis elbow. AJR Am J Roentgenol 2005;185:1113-8.

26. Murtezani A, Ibraimi Z, Vllasolli TO, Sllamniku S, Krasniqi S, Vokrri L. Exercise and Therapeutic Ultrasound Compared with Corticosteroid Injection for Chronic Lateral Epicondylitis: A Randomized Controlled Trial. Ortop Traumatol Rehabil 2015;17:351-7.

27. Binder A, Hodge G, Greenwood AM, Hazleman BL, Page Thomas DP. Is therapeutic ultrasound effective in treating soft tissue lesions? Br Med J (Clin Res Ed) 1985;290:512-4.

28. Kachanathu SJ, Vellapallil DMSNS. Pulsed versus continuous ultrasound therapy: as a management of lateral epicondylitis. IJMHS 2013;3:242-5.

29. Klaiman MD, Shrader JA, Danoff JV, Hicks JE, Pesce WJ, Ferland J. Phonophoresis versus ultrasound in the treatment of common musculoskeletal conditions. Med Sci Sports Exerc 1998;30:1349-55.

30. Rutjes AW, Nüesch E, Sterchi R, Jüni P. Therapeutic ultrasound for osteoarthritis of the knee or hip. Cochrane Database Syst Rev 2010;(1):CD003132.

31. Fu SC, Shum WT, Hung LK, Wong MW, Qin L, Chan KM. Low-intensity pulsed ultrasound on tendon healing: a study of the effect of treatment duration and treatment initiation. Am J Sports Med 2008;36:1742-9.

32. Korstjens CM, van der Rijt RH, Albers GH, Semeins CM, Klein-Nulend J. Low-intensity pulsed ultrasound affects human articular chondrocytes in vitro. Med Biol Eng Comput 2008;46:1263-70.

33. Baker KG, Robertson VJ, Duck FA. A review of therapeutic ultrasound: biophysical effects. Phys Ther 2001;81:1351-8. 
34. Norris C, editor. Sports injuries diagnosis and management. 3rd ed. Oxford: Butterworth Heinemann Elsevier Limited; 2004.

35. Nimgade A, Sullivan M, Goldman R. Physiotherapy, steroid injections, or rest for lateral epicondylosis? What the evidence suggests. Pain Pract 2005;5:203-15.

36. Gündüz R, Malas FÜ, Borman P, Kocaoğlu S, Özçakar L. Physical therapy, corticosteroid injection, and extracorporeal shock wave treatment in lateral epicondylitis. Clinical and ultrasonographical comparison. Clin Rheumatol 2012;31:807-12.

37. Aktaş S. Baskı yaraları tedavisinde terapötik ultrasonun etkileri. Atatürk Üniversitesi Tip Bülteni 1990;22:503-8.

38. Turner JA, Deyo RA, Loeser JD, Von Korff M, Fordyce WE. The importance of placebo effects in pain treatment and research. JAMA 1994;271:1609-14.

39. Zubieta JK, Stohler CS. Neurobiological mechanisms of placebo responses. Ann N Y Acad Sci 2009;1156:198-210. 